\title{
ELECTRIC LINE MAN SAFETY SYSTEM WITH OTP BASED CIRCUIT
}

\section{BREAKER}

\author{
Athira P Nair ${ }^{1}$, Josephin $\mathrm{J}^{2}$, Anjana $\mathrm{A} \mathrm{S}^{3}$, Athira C $\mathrm{P}^{4}$, Sebin J Olickal ${ }^{5}$ \\ ${ }^{I}$ Student, Dept. of Electronics \& communication, BTC College of Engineering, Koothattukulam, Kerala \\ ${ }^{2}$ Student, Dept. of Electronics \& communication, BTC College of Engineering, Koothattukulam, Kerala \\ ${ }^{3}$ Student, Dept. of Electronics \& communication, BTC College of Engineering, Koothattukulam, Kerala \\ ${ }^{4}$ Student, Dept. of Electronics \& communication, BTC College of Engineering, Koothattukulam, Kerala \\ ${ }^{5}$ Assistant Professor, Dept. of Electronics\& communication, BTC College of Engineering, Koothattukulam, Kerala
}

\begin{abstract}
The electric line man safety system make use of a new concept of one time password (OTP). It is found that fatal electrical accidents to the line man are increasing during the electric line repair due to the lack of communication and co-ordination between the maintenance staff and the electric substation staff. Hence to avoid this we are implementing a password based circuit breaker. When the user put a request the system generates passwords and a relay switches to turn ON or OFF the circuit breaker. OTP plays a major role in this system. The one time passwords mean the generated passwords are different at each time. These passwords provide total control to the system to turn on or off the supply to each line. The maintenance staff e.g. line man has the control to turn ON/OFF the line, because the line man has to put a request to the system to its working. If there is a problem in any particular section of the supply line, then staff wants to turn off that line and repair it. For that the system generates a onetime password and sends it to his phone. Using a matrix keypad he can enter it in the system. Then the system compares the entered password with the generated password. If the passwords are matched, then the supply to that line will be made OFF and the password is expired. Now he can repair the line more safely and after it is over he can turn on that line by using another password. This ensures security of the worker because no one can turn on the line without his permission. The activation or deactivation of the circuit breaker is indicating by a lamp (ON/OFF).
\end{abstract}

Keywords-OTP, GSM, Circuit breaker; Password, Wireless communication.

\section{INTRODUCTION}

Security is the prime concern in our day to day life. Everyone needs to be secure as much as possible [1].The electric line man safety system is designed to control a circuit breaker by using a password for the safety of electric man [1]. Critical electrical accidents to line men are on the rise during electric line repair due to lack of communication and co-ordination between the maintenance staff and electric substation staff [2]. This proposed system provides a solution that ensures safety of maintenance staff, i.e., line man [3]. The control to turn on or off the line will be maintained by the line man only because this system has an arrangement such that a password is required to operate the circuit breaker (on/off) [2]. The system is fully controlled by a microcontroller from AVR family. A matrix keypad is interfaced to the microcontroller to enter the password. The entered password is compared with the password generated. If the password entered is correct, only then the line can be turned ON/OFF. The basic idea behind this project is shown in the following figure.1. To repair a particular section of the electric supply line, the lineman wants to turn off the supply to that line. For this he first put a request to the system. Then the system responds to him using the LCD display to enter the password. Then the system generates a password and it will be send to the phone (the no of which is stored in the program).The password based circuit breaker can also be implemented in automatic door locking system for providing high security. And also can be implemented to control electronic appliances to save the power.

\section{LINE MAN SAFETY SYSTEM DESCRIPTION}

The electric line man safety system provides a control to turn on or off the line and thereby ensures the safety of the staff. It consists of only an embedded section. The major component is a micro controller from AVR family.

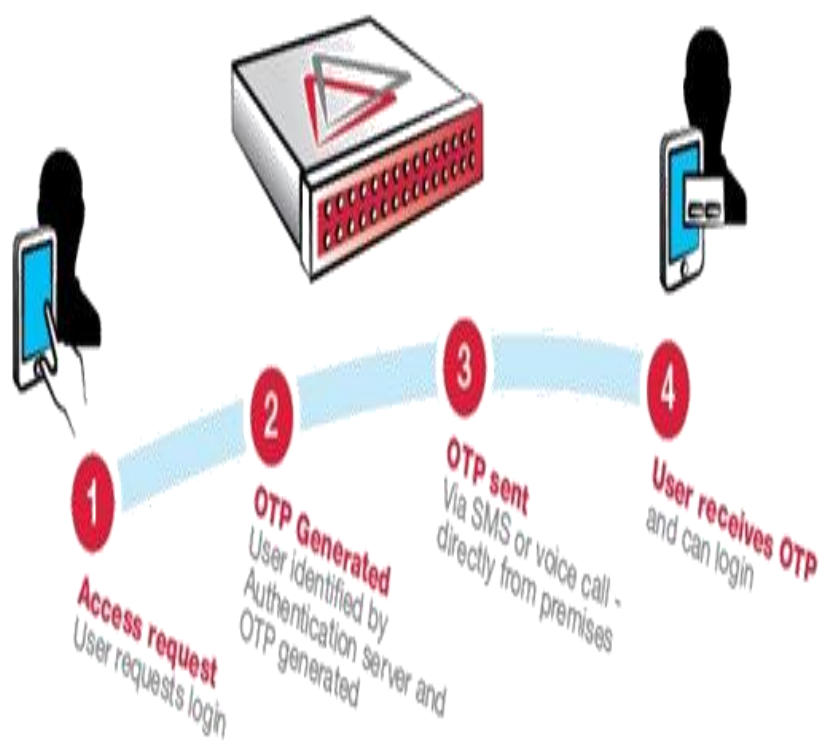

Fig 1. OTP Based System Idea 
Based on the program done in the microcontroller a relay switches to turn on or off the circuit breaker. The system comprised of a GSM module, LCD display, buzzer, matrix keypad, and a relay. The main attraction of this project is the OTP generation. The generated passwords will be different at each time and after the use of this password it will be expired. From the AVR family ATmega32 microcontroller is used. It is an 8-bit micro- controller with $32 \mathrm{~KB}$ memory and has 4 ports.

Normally the supply to the line is always on and it is indicated by using a lamp which is always on. If there is any problem in any section of the supply line, then the line man wants to turn off the supply to that section and repair it. The LCD display provided along with the system gives visual assistance of "LINE MAN SAFETY SYSTEM WITH OTP GENERATION" for easy operation of the system. For that he first put a request to the system if the system is ready. The LCD display gives an indication of "SYSTEM READY" if is ready to work. Then he put a request by pressing a switch. This gives an indication to the system to turn off the supply to the line. Then the system generates a 4-bit length onetime password. And also gives an indication of "OTP GENERATED". Then it will be send to his phone (the number of which is stored in the program) gives an indication of "OTP SEND" and "ENTER OTP". After enter it using the keypad, it will be compared with the generated password (which is stored in the ROM). If the passwords are matched, then the LCD displays "OTP MATCHED" and turn off the supply to the line i.e, the lamp will be turned off. Therefore the line man can safely work on the line and repair it. When repair is over, he will reach the substation and again put a request to turn on the supply by pressing the switch. Then system generates another password and using it he can turn on the line. If the passwords are not matched up to or more than three times, an alarm will be activates. The GSM modem provides the communication between the system and the line man. The number of the phone in to which the OTP is send is stored in the program. This number may be either of the sub engineer's number or of the line man's number. It is possible to send the number to more people. But it will be based on the security only. It is also possible to use each password for a particular line. And also wireless communication can also used depends on the distance.

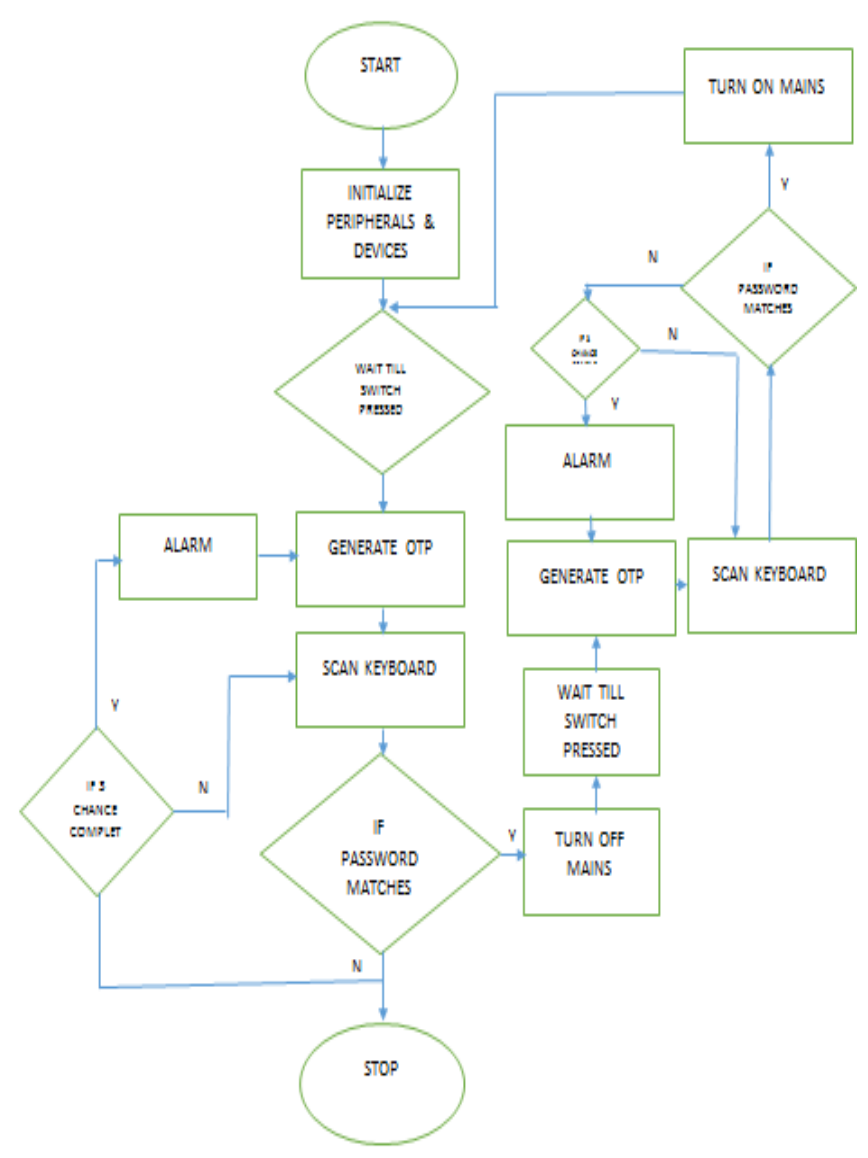

Fig 2.Flow Chart

\section{PASSWORD BASED CIRCUIT BREAKER}

\subsection{Basic Block Diagram}

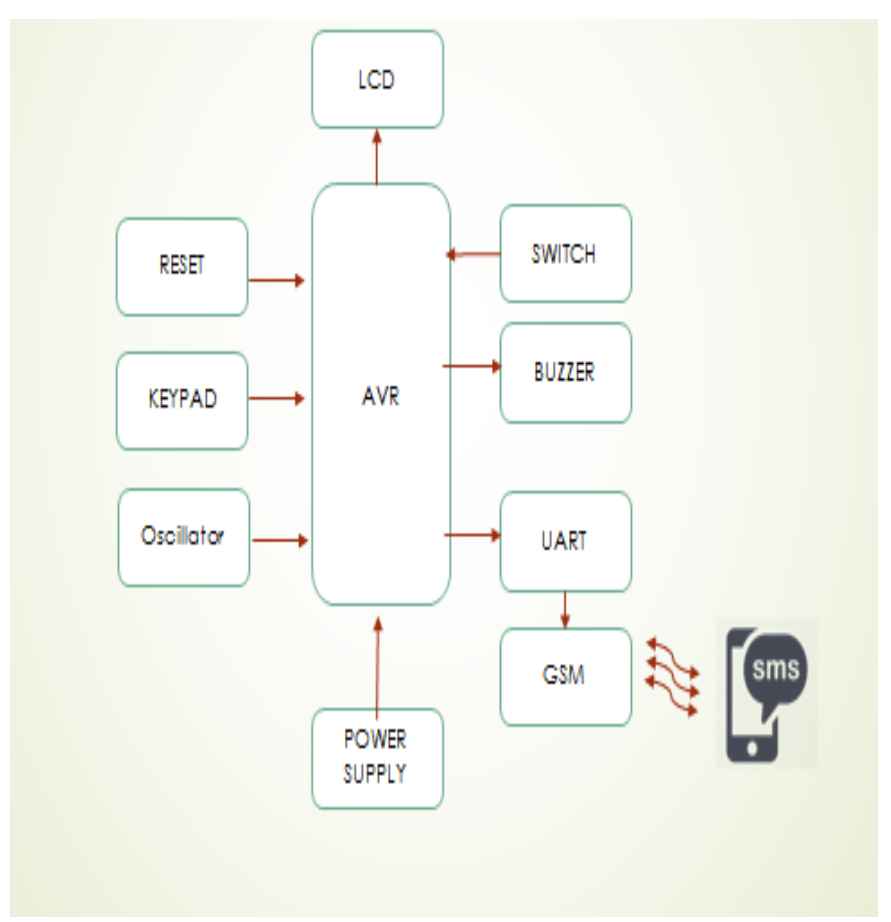

Fig.3 Basic Block Diagram 
The basic block diagram of the system is shown in the above figure.2. OTP generation and OTP verification are the major steps that are performed by this system. Depending on the request from the user the system generates OTP and it will send to the user's phone. After enter this password using the keypad, it will compared with the generated password (which is stored in the ROM). If the passwords are same, the supply to the line will be made off. Similarly using another password the power to that line will be turned on. If the passwords are not matched up to or more than three times an alarm will be generate.

\subsection{ATMEGA32}

The micro controller used for the implementation of this system is ATmega32. It is an 8-bit microcontroller with $32 \mathrm{~KB}$ on-chip programmable flash memory. Based on the program stored in the micro controller it will generate the OTP. And if the passwords are matched or not, it will switches a relay also.

The GSM modem helps to send the generated OTP. OTP generation is the main part of this project. This is done by the micro controller. The RISC based micro controller consists of four ports. In which port A is dedicated for ADC.

\subsection{LCD Display}

For ease of interaction with the user, this system uses an electronic display module. Here a $16 \times 2$ LCD is used. This means in 2 lines it is possible to display 16 characters per line. A $5 \times 8$ pixel matrix is used for display one character. Two registers are associated with an LCD, such as data and command. These modules are preferred since it is easily programmable. For providing visual assistance to the lineman this module is unavoidable.

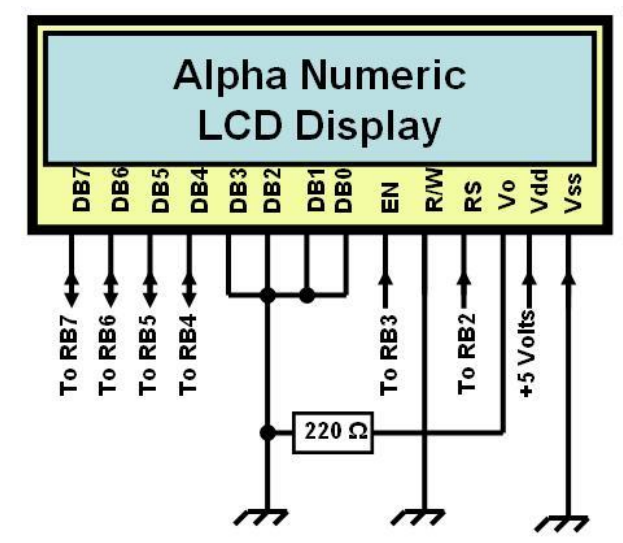

Fig.4 LCD Display

\subsection{GSM MODEM}

The Global System for Mobile Communication replaced the first generation analog cellular network. Here it is used for sending SMS to the user of the system that is the lineman. It is a dedicated modem device that accepts a SIM card and operates like a mobile phone. When it is used along with the computer, it is possible to communicate over the mobile network. Using serial communication the generated passwords are sent to the mobile phone of the user. Through the use of AT - attention commands the GSM modem can be controlled. It consists of an antenna.

Table.1.At Commands

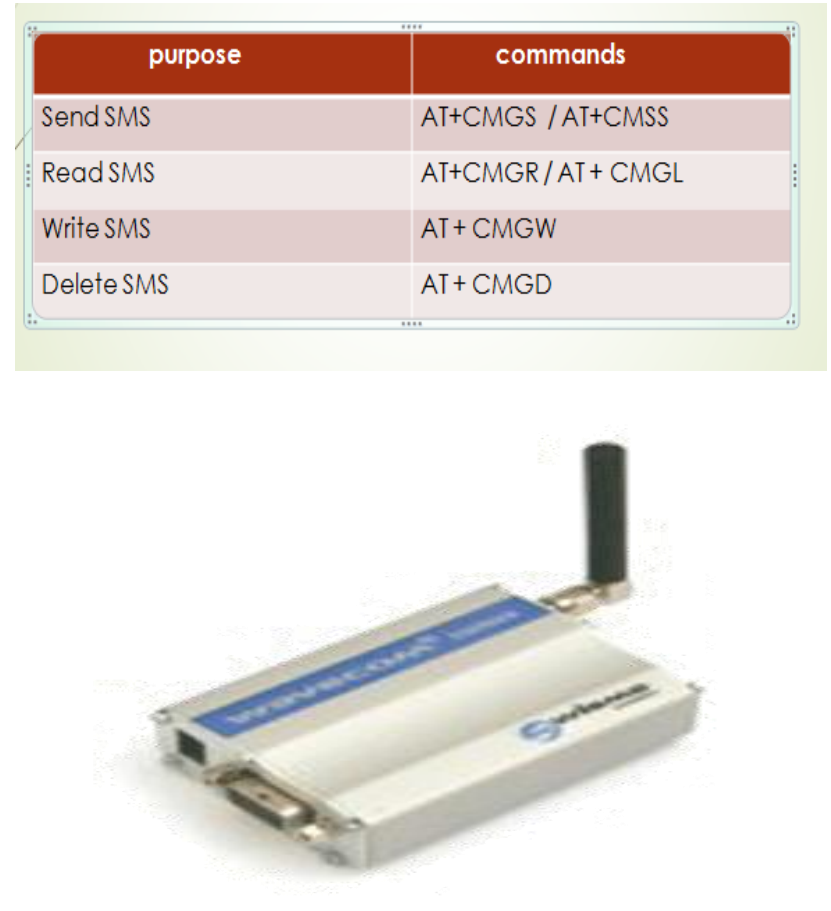

Fig.5 GSM Modem

\subsection{MAX 232}

For long distance communication parallel data communication is faster. But for this there may be more channels are necessary. Therefore the cost of the communication system also increases. So here prefer the UART serial communication. Here the baud rate used for data transmission is 9600 . The MAX 232 converts the signals from RS 232 serial port to signals suitable for use in TTL compatible digital logic circuits. It provides a connection between a serial port device to a serial port that uses RS 232 standard.

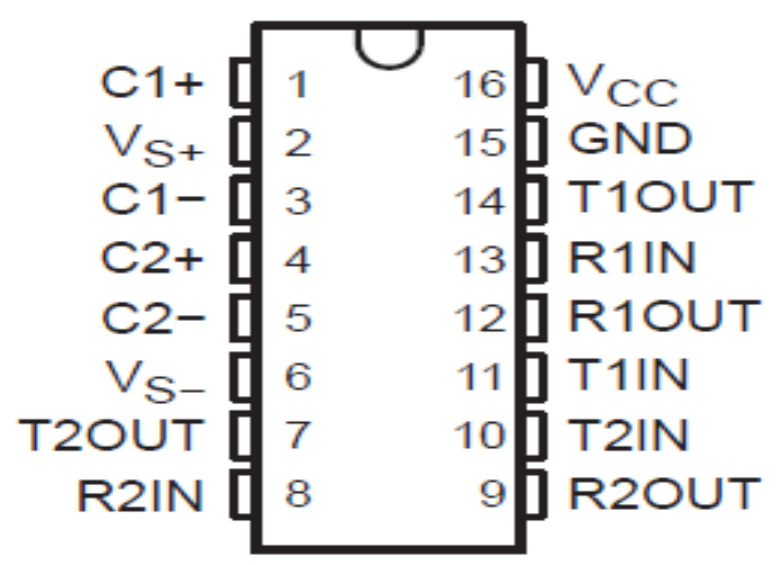

Fig.6 MAX 232 
Table 2.RS-232 Voltage Levels

\begin{tabular}{|l|l|l|}
\hline $\begin{array}{l}\text { RS232 Line Type \& } \\
\text { Logic Level }\end{array}$ & $\begin{array}{l}\text { RS232 Voltage } \\
\text { to/from } \\
\text { MAX232 }\end{array}$ \\
\hline $\begin{array}{l}\text { Data Transmission } \\
\text { (Rx/Tx) Logic 0 }\end{array}$ & $+3 \mathrm{~V}$ to +15V & $0 \mathrm{~V}$ \\
\hline $\begin{array}{l}\text { Data Transmission } \\
\text { (Rx/Tx) Logic 1 }\end{array}$ & $-3 \mathrm{~V}$ to $-15 \mathrm{~V}$ & $5 \mathrm{~V}$ \\
\hline $\begin{array}{l}\text { Control Signals } \\
\text { (RTS/CTS/DTR/DSR) } \\
\text { Logic 0 Signals }\end{array}$ & $-3 \mathrm{~V}$ to $-15 \mathrm{~V}$ & $5 \mathrm{~V}$ \\
\hline $\begin{array}{l}\text { Control to }+15 \mathrm{~V} \\
\text { (RTS/CTS/DTR/DSR) } \\
\text { Logic 1 }\end{array}$ & $0 \mathrm{~V}$ \\
\hline
\end{tabular}

\subsection{Power Supply Section}

For the working of the system a power supply is needed. The micro controller needs only 5 volt DC for its working. Therefore the incoming $\mathrm{AC}$ will be rectified filtered and regulated by $7805 \mathrm{IC}$.

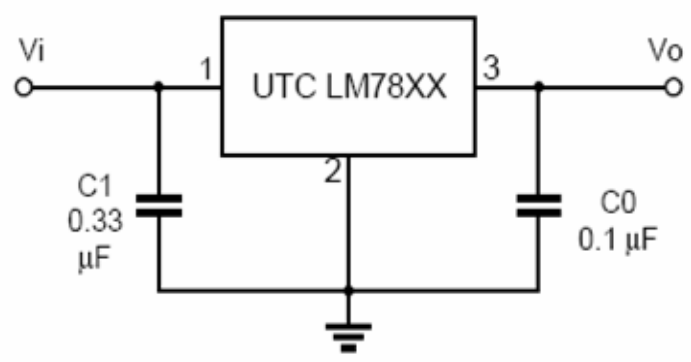

Fig.7 Voltage Regulator

\subsection{Relay}

It is basically a switch based on electromagnetic induction. Here uses a $12 \mathrm{~V}$ DC SPDT relay. It is normally open and closes when the OTPS are the same.

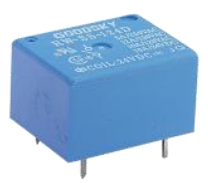

Fig.8 Relay

\subsection{Matrix Keypad}

Here it is used for entering the password. A $4 \times 4$ matrix keypad is used.

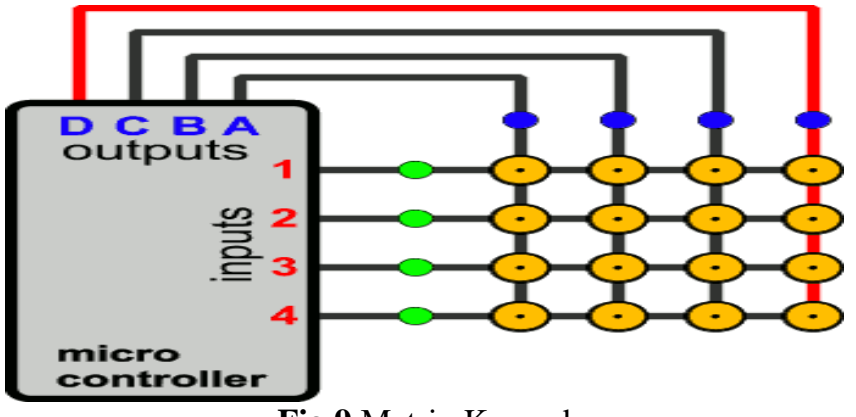

Fig.9 Matrix Keypad

\section{FUTURE APPLICATIONS}

Using wireless communication this system can be operated from other areas besides the substation such as on the transformer. The SCADA is a system used in the communication channels to help easy troubleshoot to locate the fault location directly and the line man can easily rectify it.

\section{CONCLUSION}

The electric line man safety system is designed to control a circuit breaker with help of a password only. OTP generation and OTP verification are the major tasks involved in this system. OTP generation is the main attraction of this project. It provides a new approach to the security of the lineman and completely eliminates the accidents to the lineman due to electric shock during the electric line repair. This system can also implement in many other public areas also.

\section{LIMITATIONS}

The network problems will affect the proper working of the system. Since it contain a GSM modem. There should be sufficient balance in the SIM also.

\section{REFERENCES}

[1]. IEEE Engineering in Medicine and Biology Magazine 15(1): 116-120, 1996 and 15(2):106-110, 1996.

[2]. National Electrical Safety Code Committee, Accredited Standards Committee C2 Rule 441 Table 441-1 AC Live Work Minimum Approach Distance (2002 Edition, page 228) IR540.

[3]. National Electrical Safety Code, 1997 Edition

[4]. International Journal of Engineering Trends and Technology (IJETT) - Volume 13 Number 3 - Jul 2014 